\title{
A Comparison of Two Methods for Detecting Attack on Glucose by Pseudomonads and Achromobacters
}

\author{
By R. W. A. PAR K \\ Microbiology Department, University of Reading \\ (Accepted for publication 10 October 1966)
}

SUMMARY

One hundred and forty-eight Gram-negative bacteria, mostly pseudomonads and achromobacters, were tested for glucose utilization by detection of acid production and by an enzymic method for detecting residual glucose. The enzyme test showed that some bacteria which produced little or no acid in glucose media (e.g. Pseudomonas maltophilia, Pseudomonas groups III and IV of Shewan, Hobbs \& Hodgkiss, 1960) did remove glucose from the media. Representatives of the genus Comamonas did not produce acid from glucose or remove it.

\section{INTRODUCTION}

Hugh \& Leifson (1953) used acid production to show whether bacteria attacked carbohydrates fermentatively, oxidatively or not at all (oxidation versus fermentation test; $\mathrm{O} / \mathrm{F}$ test). The test has been modified for certain types of bacteria (Baird-Parker, 1963) or to give greater sensitivity (Board \& Holding, 1960; Scholefield, 1962). In assessment of the reliability of their O/F test, Board \& Holding (1960) found that only strains which produced acid showed oxygen uptake when glucose was used as substrate in the Warburg apparatus. However, in cases where it is difficult to decide whether any acid has been produced from glucose, a simpler alternative method for detecting attack on glucose is required. This note describes the application of such a method to several non-fermentative Gram-negative bacteria. It consists of incubating bacteria in a glucose-containing medium and using a simple enzymic method (glucose oxidase + peroxidase $+o$-tolidine) to determine whether any glucose remains after incubation.

\section{METHODS}

Strains. Various Gram-negative bacteria, mostly pseudomonads and achromobacters, were obtained from the National Collection of Type Cultures, the National Collection of Industrial Bacteria, the National Collection of Marine Bacteria, various members of the Pseudomonas Working Party and the author's own collection. They were maintained on heart infusion agar (Difco) slopes in screw-capped bottles.

Inoculation and incubation of tests. Liquid media were inoculated with a $2 \mathrm{~mm}$. loop and semi-solid media by stabbing with a straight wire. Nutrient broth cultures incubated at $25^{\circ}$ for $24 \mathrm{hr}$, or in the case of slow-growing strains for $48 \mathrm{hr}$, were used for the inocula. Results were recorded after incubation at $25^{\circ}$ for 1 day and 7 days.

Oxidation versus fermentation $(O / F)$ tests which use acid production to indicate attack on glucose. The general procedure followed was that described by Hugh \& Leifson (1953) but it was not necessary to incubate a duplicate set of tubes under a 
seal. The basal medium used here had the following composition: peptone (Evans), 2.0 g.; NaCl, 5.0 g.; $\mathrm{K}_{2} \mathrm{HPO}_{4}, 0.3 \mathrm{~g}$.; agar No. 3 (Oxoid), 3.0 g.; $1 \%$ (w/v) aqueous solution of bromothymol blue, $8 \mathrm{ml}$; in 11 . demineralized water; $\mathrm{pH} 7 \cdot 2$. When required, glucose $(10 \%, \mathrm{w} / \mathrm{v}$, filter-sterilized solution) was added at the rate of $10 \mathrm{ml}$. solution/100 ml. molten basal medium. Each strain was inoculated into 1 tube of the basal medium + glucose and 1 tube of the basal medium alone. Tests were also made with: the medium described above but with Casitone (Difco) in place of Evans peptone; the Difco $\mathrm{O} / \mathrm{F}$ basal medium; the $\mathrm{O} / \mathrm{F}$ medium described by Hugh \& Ryschenkow (1961); the O/F (2) medium of Scholefield (1962).

Enzymic method for demonstrating glucose disappearance. 'Clinistix' reagent strips (Miles Laboratories, Stoke Poges, Buckinghamshire), which are sensitive to $0.01 \%$ $(\mathrm{w} / \mathrm{v})$ glucose, are strips of paper impregnated with glucose oxidase (an enzyme specific for glucose; Keilin \& Hartree, 1948) + peroxidase $+o$-tolidine. From glucose, glucose oxidase produces acid and hydrogen peroxide, and this hydrogen peroxide in the presence of peroxidase then oxidizes the $o$-tolidine to a blue compound.

Two kinds of false readings may be expected when these reagent strips are used to detect glucose in cultures of bacteria: (i) reducing substances may inhibit development of colour on the strip so that glucose, though present, is not detected; (ii) any hydrogen peroxide present will give a blue colour on the strip, whether or not glucose is present.

To use this enzymic method for detecting ability to attack glucose the following procedure was adopted. A liquid medium similar to the Hugh \& Leifson (1953) medium but lacking agar and bromothymol blue was prepared. It was called MHL medium and it consisted of Evans peptone, $2.0 \mathrm{~g}$.; NaCl, $5 \cdot 0 \mathrm{~g} . ; \mathrm{K}_{2} \mathrm{HPO}_{4}, 0.3 \mathrm{~g} . ;$ in

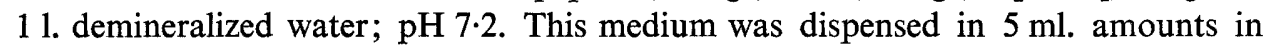
$25 \times 150 \mathrm{~mm}$. tubes and when required glucose as a filter-sterilized solution was added to a final concentration of $0.05 \%(\mathrm{w} / \mathrm{v})$. For each strain a tube of MHL medium + glucose ( $+\mathrm{G}$ medium) and a tube of MHL medium alone ( $-\mathrm{G}$ medium) were inoculated and incubated in a sloped position for 7 days. After 1 day and 7 days a loopful of each culture was put on a Clinistix reagent strip which was examined after $1 \mathrm{~min}$. When, at 7 days, no blue colour appeared with a $+\mathrm{G}$ culture, glucose $(0.05 \%, \mathrm{w} / \mathrm{v})$ was added, and the culture immediately retested. No colour on the strip after this would indicate that inhibitors of the test were present. Four results are theoretically possible from examining two tubes in this way.

(1) Absence of colour from strip treated with $+G$ and $-G$ cultures would indicate one of three alternatives: (a) that glucose had disappeared from the $+\mathrm{G}$ culture and an inhibitor for the development of colour on the strip had not been produced by the culture; $(b)$ that glucose remained but an inhibitor had been produced $(c)$ that glucose had disppeared from the $+\mathrm{G}$ culture and an inhibitor had been produced. The possibility that an inhibitor had been produced can be eliminated by adding glucose to the $+\mathrm{G}$ cultures and retesting, as described above. On no occasion was an inhibitor detected and so with the organisms used in this work it was not necessary to distinguish between alternatives $(b)$ and $(c)$.

(2) Colour on strips impregnated with $+G$ culture but not on those impregnated with $-G$ culture would indicate that glucose remained in the $+G$ culture after incubation and that $\mathrm{H}_{2} \mathrm{O}_{2}$ production was not interfering with the test.

(3) Colour on strips impregnated with $+G$ culture and with $-G$ culture would 
indicate that production of $\mathrm{H}_{2} \mathrm{O}_{2}$ was interfering with the test. In no case did this occur. It is possible that inhibition of catalase by acids might allow $\mathrm{H}_{2} \mathrm{O}_{2}$ to accumulate more in a glucose-containing culture, so making valueless the use of $\mathrm{a}-\mathrm{G}$ culture to control this possibility. In doubtful cases the following method was used to confirm that $\mathrm{H}_{2} \mathrm{O}_{2}$ production was not interfering with the test. To $1 \mathrm{ml}$. culture grown in $-\mathrm{G}$ medium was added $0.05 \mathrm{ml}$. ' 10 vol.' $\mathrm{H}_{2} \mathrm{O}_{2}$, sufficient, to make the culture give an intense reaction with the strips. To this, and to $1 \mathrm{ml}$. of culture in $+\mathrm{G}$ medium, was added $0.1 \mathrm{ml}$. iodine solution (iodine, $0 \cdot 3 \mathrm{~g}$.; potassium iodide, $0 \cdot 6 \mathrm{~g}$.; distilled water, $90 \mathrm{ml}$.) and after heating in boiling water for $5 \mathrm{~min}$. both cultures were tested with Clinistix strips. The procedure removed any peroxide present, as indicated by the $-\mathrm{G}$ culture giving no blue reaction, so that any blue reaction with the $+G$ culture indicated that glucose was in fact still present after incubation.

(4) Colour on strips impregnated with $-G$ culture but not on those impregnated with $+\mathrm{G}$ culture. This result is unlikely and did not occur.

The enzymic method for detecting glucose utilization was also tested with two other media. These were nutrient broth $(\%, \mathrm{w} / \mathrm{v}$; Evans peptone, $0.5 ;$ Lab. Lemco, 0.5 ; $\mathrm{NaCl}, 0 \cdot 5$; in distilled water; $\mathrm{pH} 7 \cdot 2$ ) and $\mathrm{MBH}$ medium which was the basal medium of Board \& Holding (1960) but without agar $\left(\%\right.$, w/v: $\mathrm{NH}_{4} \mathrm{H}_{2} \mathrm{PO}_{4}, 0.05 ; \mathrm{K}_{2} \mathrm{HPO}_{4}$, 0.05; Difco yeast extract, 0.05; mineral supplement; in distilled water; $\mathrm{pH} 7 \cdot 2$ ).

\section{RESULTS}

One hundred and forty-eight Gram-negative bacteria, mostly pseudomonads and achromobacters from a variety of habitats, were examined for ability to produce acid from glucose, by using various oxidation versus fermentation $(\mathrm{O} / \mathrm{F})$ tests, and for ability to remove glucose from liquid cultures by using the enzyme strips. Most strains gave comparable results in these tests (Table 1). Sixty-two strains produced

Table 1. Comparison of results obtained by two methods for detecting attack on glucose by various Gram-negative bacteria, mostly pseudomonads and achromobacters

\begin{tabular}{|c|c|c|c|}
\hline \multirow[b]{2}{*}{$\begin{array}{l}\text { No. of } \\
\text { strains } \\
\text { tested }\end{array}$} & \multirow{2}{*}{$\begin{array}{c}\text { Attack detected by showing } \\
\text { that cultures produced acid } \\
\text { in various oxidation } v \text {. } \\
\text { fermentation test media }+ \text { glucose } \\
(1 \%) \text {. Reaction after incuba- } \\
\text { tion for } 7 \text { days at } 25^{\circ}\end{array}$} & \multicolumn{2}{|c|}{$\begin{array}{l}\text { Attack detected by showing with an enzyme } \\
\text { reagent strip that after } 7 \text { days at } 25^{\circ} \\
\text { glucose had been removed from: }\end{array}$} \\
\hline & & $\begin{array}{l}\text { Cultures in } \\
\text { MHL medium*+glucose } \\
(0.05 \%)\end{array}$ & $\begin{array}{l}\text { Cultures in } \\
\text { nutrient broth }+ \text { glucose } \\
(0.05 \%)\end{array}$ \\
\hline 62 & Acid & Glucose removed & Glucose removed \\
\hline 2 & Acid & Glucose removed & Glucose remained \\
\hline 59 & Alkaline & Glucose remained & Glucose remained \\
\hline 25 & $\begin{array}{l}\text { Slight acid or alkaline or } \\
\text { no change }\end{array}$ & Glucose removed & Glucose removed \\
\hline
\end{tabular}

* MHL medium was similar to the medium of Hugh \& Leifson (1953) but lacked agar and bromothymol blue.

acid from glucose in all varieties of the $\mathrm{O} / \mathrm{F}$ test and removed glucose from cultures in + G MHL medium and in $+G$ nutrient broth. Not all strains grew well in $\mathrm{MBH}$ medium but all those which did do so removed glucose from the $+G$ cultures. Attack 
on glucose was detected after $24 \mathrm{hr}$ more frequently by the enzyme test that by the $\mathrm{O} / \mathrm{F}$ test. Two strains produced acid in $\mathrm{O} / \mathrm{F}$ tests and removed glucose from $+\mathrm{G}$ MHL medium, but did not remove glucose from $+\mathrm{G}$ nutrient broth or grow in $+\mathrm{G} \mathrm{MBH}$ medium. Fifty-nine strains did not produce acid from glucose in any varieties of the $\mathrm{O} / \mathrm{F}$ test (in all cases an alkaline reaction developed) or remove glucose from $+\mathrm{G}$ cultures.

Table 2. Strains which removed glucose from liquid media, as shown by an enzyme test, but which produced little or no acid from glucose in Hugh \& Leifson glucose medium

Pseudomonas maltophilia (designated type strain of the species by Hugh \& Ryschenkow, 1961) ATCC13637, NCTC 10257; supplied by Dr R. Hugh, no. 810-2

$P$. maltophilia ATCC13636; supplied by Dr R. Hugh, no. 560

$P$. maltophilia ATCC13843; supplied by Dr R. Hugh, no. 611

$P$. nigrifaciens NCIB 8614

$P$. oleovorans NCIB 6576

$P$. putrefaciens NCIB 8615

'Brown' organisms; supplied by Dr Margaret Thornley, nos. EB/F44/1, EB/F44/15, EB/F44/84, EB/F $44 / 148$

Gram negative bacteria from cheese; supplied by Dr M. Elizabeth Sharpe, nos. GN39, GN 48, GN49, GN50, GN52, GN53

Pseudomonas group III (Shewan, Hobbs \& Hodgkiss, 1960) NCMB 224

Pseudomonas group IV (Shewan et al. 1960) NCMB 114

Pseudomonas group IV (Shewan et al. 1960) NCMB 130

Pseudomonas fluorescent group A (Holding, 1960); supplied by Dr A. J. Holding, no. PT 2

Agrobacterium; supplied by Dr A. J. Holding, no. LK 11

Agrobacterium; supplied by Dr A. J. Holding, no. ZM1

Pseudomonad producing gas from nitrate. Isolated by Miss Caroline Scarlett; Park no. 284

Vibrio alcaligenes NCTC 7048

Melanin-producing vibrio; supplied by Dr D. G. Smith

Twenty-five strains (see Table 2) gave indefinite results in $\mathrm{O} / \mathrm{F}$ tests. Some strains did not change the $\mathrm{pH}$ value of $\mathrm{O} / \mathrm{F}$ media during growth in the presence of glucose. Other strains produced a very weak acid reaction at the surface of $\mathrm{O} / \mathrm{F}$ media in the presence of glucose, the medium becoming lighter green or yellow-green. A few strains gave an alkaline reaction in $\mathrm{O} / \mathrm{F}$ media containing glucose. All these strains gave an alkaline reaction in $\mathrm{O} / \mathrm{F}$ media without glucose so that, in most cases, there was a difference in $\mathrm{pH}$ value at the surface of media, with and without glucose. However, these differences were slight and the results of the tests difficult to interpret. It was in these cases that the enzyme method for detecting glucose disappearance was useful. All 25 of these strains (Table 2) removed glucose from + G MHL medium and from $+\mathrm{G}$ nutrient broth. Not all strains grew in $+\mathrm{G} \mathrm{MBH}$ medium but those that did do so removed glucose.

\section{DISCUSSION}

An enzyme method for detecting the disappearance of glucose from liquid media showed that 25 strains of Gram-negative bacteria which gave indefinite results in the Hugh \& Leifson (1953) O/F test were capable of metabolizing the sugar. The enzyme method is simple to use and has the advantage that it does not depend on the ability of an organism to use glucose as a sole carbon source or to decrease the $\mathrm{pH}$ value of a glucose-containing medium. It can be performed in a liquid medium like that described by Hugh \& Leifson (1953) but lacking agar and bromothymol blue (MHL medium). 
It is necessary to incubate the culture in $25+150 \mathrm{~mm}$. tubes in the sloped position because strains which oxidize glucose leave sufficient sugar to give a reaction in the enzyme test when the medium is in $15+150 \mathrm{~mm}$. tubes incubated vertically. A nutrient broth base, though generally satisfactory for the enzyme test, is not recommended because two strains (both achromobacters) which produced acid in O/F glucose tests and removed glucose from $+\mathrm{G}$ MHL medium without indicator did not always remove glucose from $+\mathrm{G}$ nutrient broth. This was presumably because components of the peptone and Lab Lemco were used in preference to glucose. A similar diauxic effect, in which citrate was used by Pseudomonas aeruginosa in preference to glucose, was reported by Hamilton \& Dawes $(1959,1961)$.

The enzyme test showed that Pseudomonas maltophilia strains attacked glucose. Hugh \& Ryschenkow (1961) reported that $P$. maltophilia did not produce acid from glucose except some old laboratory strains which produced a very weak acid reaction after prolonged incubation. The three strains examined by me (see Table 1) produced little or no acid at 7 days in $\mathrm{O} / \mathrm{F}$ media which contained glucose but were shown by the enzyme method to attack glucose. Stanier, Palleroni \& Doudoroff (1966) found that $P$. maltophilia utilized glucose as carbon + energy source when methionine, required as a growth factor, was present. Representatives of Pseudomonas group III and group IV of Shewan et al. (1960), which by definition do not produce acid in O/F glucose media, were found to attack glucose when tested by the enzyme method (Table 1).

It was confirmed by the enzyme method that representatives of strains which were classified as Comamonas by Davis \& Park (1962) and Park (1962) did not attack glucose. These strains (Park nos. 11, 13, 23, 100; Pseudomonas putrefaciens NCIB 8615; Comamonas percolans NCTC1937; Vibrio cyclosites, NCIB 2581; V. neocystes, NCIB 2582; $V$. alcaligenes, NCTC9239) previously had been shown not to produce acid in $\mathrm{O} / \mathrm{F}$ glucose media or to utilize glucose as a sole carbon +energy source. Strains of $P$. alcaligenes from Dr R. Hugh, (R. Hugh nos. 1155, 1278, 1288) and of Comamonas terrigena (R. Hugh nos. 31, 32, 37, 131, 1884) and the type strain of Pseudomonas alcaligenes NCTC 10367 were also shown by the enzyme method not to attack glucose. The taxonomic position of these strains with respect to the classification of Stanier et al. (1966) is not clear because, with the exception of the type strain of Pseudomonas alcaligenes, they do not appear to have been examined for nutritional pattern. Some are likely to be members of the acidovorans group or the alcaligenes group, but not all strains previously classified as Comamonas can be integrated into the scheme at present because the type strain of the genus C. terrigena (C. percolans NCTC1937, ATCC8461) has not yet been grown on a chemically defined medium (Stanier $e t$ al. 1966).

I wish to thank Dr D. G. Smith for suggesting the use of enzyme reagent strips and Dr M. Elizabeth Sharpe, Dr R. Hugh and members of the Pseudomonas Working Party for providing cultures. The technical assistance of Mrs P. Hardy and Mr M. Marriott is also gratefully acknowledged. 


\section{REFERENCES}

BAIRD-PARKer, A. C. (1963). A classification of micrococci and staphylococci based on physiological and biochemical tests. J. gen. Microbiol. 30, 409.

BOARD, R. G. \& HoldiNG, A. J. (1960). The utilization of glucose by aerobic Gram-negative bacteria. J. appl. Bact. 23, xi.

Davis, G. H. G. \& Park, R. W. A. (1962). A taxonomic study of certain bacteria currently classified as Vibrio species. J. gen. Microbiol. 27, 101.

Hamilton, W. A. \& Dawes, E. A. (1959). A diauxic effect with Pseudomonas aeruginosa. Biochem. J. 71, $25 \mathrm{P}$.

Hamilton, W. A. \& Dawes, E. A. (1961). Further observations on the nature of the diauxic effect with Pseudomonas aeruginosa. Biochem. J. 79, $25 \mathrm{P}$.

Holding, A. J. (1960). The properties and classification of the predominant Gram-negative bacteria occurring in soil. J. appl. Bact. 23, 515.

Hugh, R. \& Leifson, E. (1953). The taxonomic significance of fermentative verus oxidative metabolism of carbohydrates by various Gram-negative bacteria. J. Bact. 66, 24.

Hugh, R. \& RYSCHENKow, E. (1961). Pseudomonas maltophilia, an alcaligenes-like species. J. gen. Microbiol. 26, 123.

Keilin, D. \& Hartree, E. F. (1948). Properties of glucose oxidase (Notatin). Biochem. J. 42, 221.

PARK, R. W. A. (1962). A study of certain heterotrophic polarly flagellate water bacteria: Aeromonas, Pseudomonas and Comamonas. J. gen. Microbiol. 27, 121.

SCHOLEFIELD, J. (1962). The effect of temperature on the biochemical activities of psychrophiles obtained from milk. M.Sc. thesis, University of Leeds.

ShewAN, J. M., HobBs, G. \& HodGkiss, W. (1960). A determinative scheme for the identification of certain genera of Gram-negative bacteria, with special reference to the Pseudomonadaceae. J. appl. Bact. 23, 379.

Stanier, R. Y., Palleroni, N. J. \& Doudoroff, M. (1966). The aerobic pseudomonads: a taxonomic study. J. gen. Microbiol. 43, 159. 